\title{
Using the Home-School-Community Model to Enhance the Chinese Language Proficiency of Non-Chinese Speaking Children
}

\author{
Shek-Kam Tse*, Heiken To, Emily Y. W. Pang, Pik-Fong Tsui, Lu-Sai Lam, Victor Laing, \\ Kam-Fong Wu
}

Faculty of Education, The University of Hong Kong, Hong Kong, China

Email: ^sktsebrian@gmail.com

How to cite this paper: Tse, S.-K., To, H., Pang, E. Y. W., Tsui, P.-F., Lam, L.-S., Laing, V., \& Wu, K.-F. (2020). Using the Home-School-Community Model to Enhance the Chinese Language Proficiency of Non-Chinese Speaking Children. Creative Education, 11, 2069-2095.

https://doi.org/10.4236/ce.2020.1110151

Received: August 27, 2020

Accepted: October 20, 2020

Published: October 23, 2020

Copyright $\odot 2020$ by author(s) and Scientific Research Publishing Inc. This work is licensed under the Creative Commons Attribution International License (CC BY 4.0).

http://creativecommons.org/licenses/by/4.0/

cc) (i) Open Access

\begin{abstract}
This study employed a mixed-method approach from multiple source of informants, including NCS students, parents, principals, teachers, multicultural teaching assistants (MTAs), and voluntary agencies to validate the effectiveness of using the Home-School-Community (H-S-C) framework in teaching Chinese to non-Chinese-speaking (NCS) children. Results revealed that NCS students receiving the H-S-C-based interventions showed a better Chinese language proficiency progression than the comparison group. Within the home domain, NCS parents increased awareness, knowledge and skills in supporting children's learning, and provided improved space for learning Chinese at home. In the school domain, principals and teachers were equipped with culturally-responsive pedagogical knowledge and skills in teaching NCS students, with MTAs' assisting in teaching and communicating with parents and teachers. Community domain programs provided experiential learning opportunities for NCS students to know the community and engage in cultural exchange with local students. With a holistic approach to home-school-community domains, a reconstruction of an L1-like Chinese language learning environment was made possible for NCS students.
\end{abstract}

\section{Keywords}

Home-School-Community Framework, Non-Chinese Pre-Schoolers, Holistic Approach, Chinese Learning, Mixed-Method, Chinese as a Second Language

\section{Introduction}

Finding effective ways to help minority-language populations learn a second language in their host countries and communities has been discussed in different 
studies (Legault et al., 2019; Choi \& Ziegler, 2015). In 2016, the number of ethnic minorities (EM) in Hong Kong constituted 3.6\% of the whole population (excluding foreign domestic helpers), with the figure on a rising trend. To integrate into a society where Chinese (spoken in Cantonese and written in traditional characters) is the predominant language, having a sufficient level of Chinese proficiency is obviously crucial; however, non-Chinese speaking (NCS) students have consistently reported great difficulties in learning Chinese, lagging behind in Chinese language proficiency when compared with the local Chinese-speaking (CS) students at the same age or grade level (Equal Opportunity Commission (EOC), 2019). In current general practice, Chinese, a predominant language in the local context, is not separately taught as a subject under the local kindergarten curriculum in the government-subsidized kindergartens (Curriculum Development Council, 2006). Instead, Chinese is taught across curriculum. As kindergartens usually adopt theme-based integrated approach, preschoolers learn Chinese through activities under different themes. As a result, establishing a model that can assist NCS students to learn Chinese effectively is a main concern for many early childhood educators. In the following, the present situation of NCS students in learning Chinese will be first examined. Next, a project using a home-school-community framework to address the issues encountered by NCS students in learning Chinese will be introduced with literature review on the theoretical underpinnings on how the three domains are associated with children's learning. Then, different evaluations under the project for the contribution of Chinese language learning development in local NCS kindergarteners will be presented. Finally, implications generated from the evaluation findings on successful Chinese learning of NCS students will be discussed.

\subsection{Issues Encountered by NCS Students in Learning Chinese}

The difficulties NCS students faced in learning Chinese can be understood in several aspects. First of all, as Chinese is a language of logographic writing system without the grapheme-phoneme correspondence (Chen et al., 2009), learning the language may be difficult for NCS students. In terms of writing Chinese characters, which is the basic complete unit in written form, emphasis is on both the stroke order and radical or component combination. Given the features of the Chinese language, it would be cognitively demanding for NCS students to learn the language well.

Secondly, there is a lack of language environment support for NCS students. NCS students do not systematically learn Chinese at kindergarten until the language is taught as a subject beginning from Primary 1 in the local mainstream primary education (Curriculum Development Council, 1996) and they are not encouraged to use the locally predominant language outside school. They usually live in communities clustered with people of the same race (EOC, 2019), and most of their parents do not provide an environment that is favorable in learning or using Chinese in their children's recreational time (Tsung \& Gao, 2012). The strong attachment to their own culture and the isolation of themselves from 
the mainstream Chinese culture has limited NCS students' opportunities for fostering their ability in the Chinese language.

Thirdly, learning materials and teacher quality are also factors that hinder the Chinese learning of NCS students. Currently, learning and teaching materials used in the local mainstream kindergartens are designed to target local Chinese-speaking children without considering the Chinese language ability of NCS students (EOC, 2019). Kindergarten teachers in the local mainstream system have no training on teaching NCS students (EOC, 2019). They have limited knowledge of the culture and language of the EM students, hindering the smooth communication between teachers and NCS parents in terms of understanding the learning progress of NCS students at school and their learning support needs at home.

\subsection{Hong Kong Government Assistance to NCS Students}

In 2016, the school attendance rate of NCS students at age group 3 - 5 was 90.7\% (Census and Statistics Department, 2017). In recent years, the Hong Kong government has emphasized NCS children's learning of the Chinese language to begin as early as kindergarten schooling in the local early childhood education curriculum. However, the existing support measures are not enough for NCS students to catch up with the local curriculum, which is planned in accordance with the Chinese language abilities of children who speak Chinese as the first language. Despite a series of support measures for NCS students in primary and secondary schools, similar support measures have yet to cover kindergartens. Although kindergartens having NCS students' intake could use the extra subsidy to hire teaching staff (Government of HKSAR, 2016), most of these recruited staff have not been equipped with pedagogical knowledge and skills to teach and take care of NCS students. Regarding home-school cooperation in Hong Kong, the establishment of Parent-teacher Associations (PTAs) at school level has been promoted, for over 30 years, for better communication between home and school and to encourage parents to take a more active role in school decisions. However, PTAs only exist in one-third of the kindergartens, with some mentioning the problem of a language barrier that is hindering the communication between parents of NCS students, their teachers and Chinese parents. Responses to the needs of NCS parents and parent education, and facilitation of the establishment of PTAs in kindergartens have been stressed (Task Force on Home School Co-operation and Parent Education, 2019).

\section{C-for-Chinese@JC Project}

In view of the above, The Hong Kong Jockey Club Charities Trust has initiated the C-for-Chinese@JC project with the goal to enhance Chinese language learning for local NCS students at the kindergarten level, with a holistic model comprising three sectors: school, home, and community, which is the first of its kind to introduce a conceptual framework for NCS kindergarteners to learn Chinese (Figure 1). 


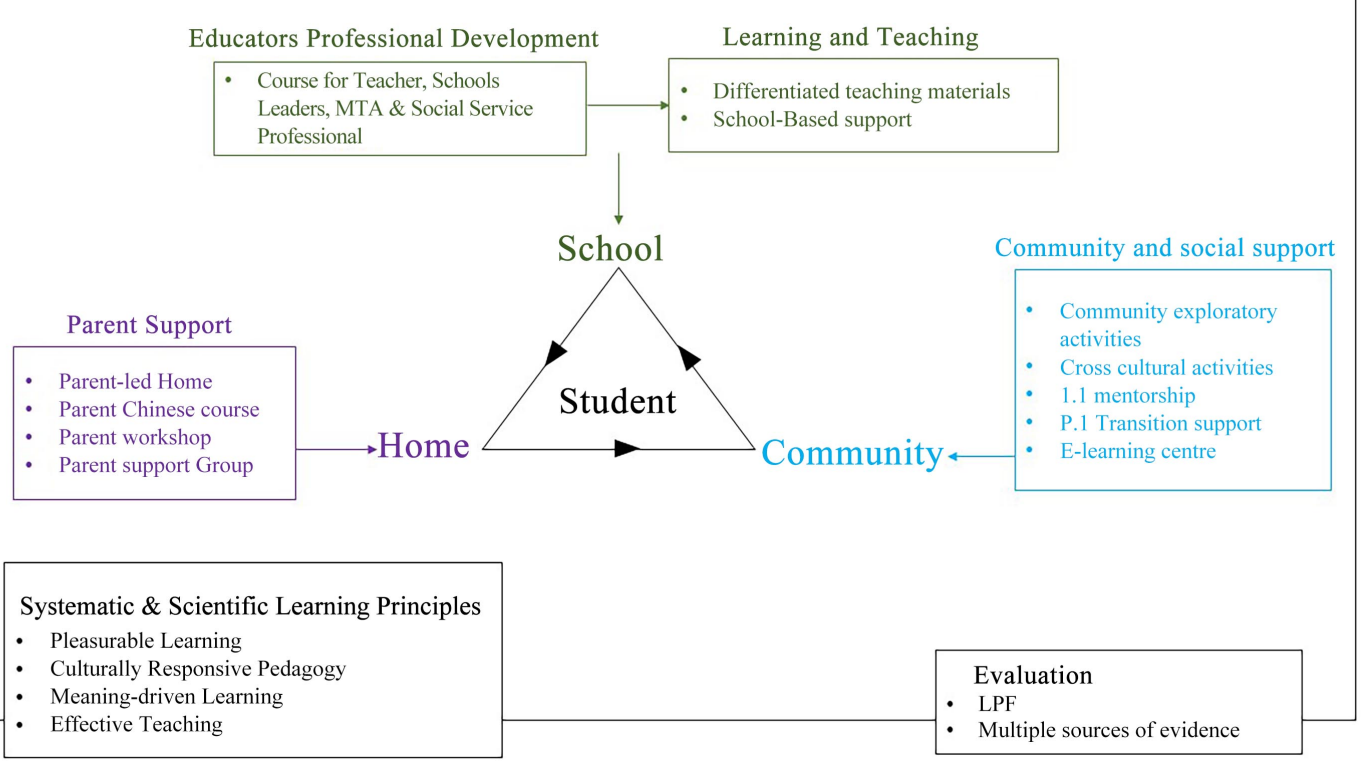

Figure 1. Inputs, services and programmes under the H-S-C framework.

Under the three domains of school, home, and community are a range of inputs, services and programs function of the intervention programs of the project, directly or indirectly, for supporting NCS preschoolers to learn Chinese. In the school domain, it is divided into educators' professional development, and learning and teaching, with the former focusing on knowledge and skill enhancement of educators and professionals, and the latter emphasizing on pedagogical and curriculum support as well as assessment. The home domain includes various trainings targeting NCS parents' facilitation for their children's learning of the Chinese language. The community domain branches into community and social support and e-learning development; the former is about the provision of activities and services and the latter is about center-based learning and service delivery learning mode.

\section{Literature Review of Home-School-Community Framework}

Home-school-community (H-S-C) collaboration has been found to be imperative for students to grow up with academic, emotional, and social success (Henderson \& Mapp, 2002; Pomerantz et al., 2007; Sheldon, 2007). As stated by Epstein (1994), the term "school, family, and community partnerships" expresses "the shared interests, responsibilities, investments, and the overlapping influences of family, school, and community for the education and development of children they share across the school years" (p. 39) and it allows different stakeholders (parents, teachers, principals, community organizations and local leaders) to work together for the betterment of the children's academic pursuit on the ground that the life success of the children also means the better future of the community and of the family. 
H-S-C framework is developed based on Bronfenbrenner's Ecological Systems Theory (1993), which explains that the child is in the center of different settings and influenced by five levels of systems. The first level is the microsystem which contains the child's direct contacts, such as family members, friends, neighbors, and teachers. The face-to-face interactions with people in home, school, and community make a strong influence on the child's growth and development. The next system is the mesosystem which is related to the microsystem in that includes the influences of all the relationships existing in the microsystem. For instance, the child's relationship with friends may affect his/her home and school life. The third level is the exosystem in which the child is influenced by non-direct contacts. The requirement to work for long hours leads to less time for parents to spend with the child, for example. The fourth level is the macrosystem which is the larger societal influence of cultural beliefs and values. The fifth level is the chronosystem in which the child is influenced by the time of his or her generation. As all the levels of influence are reciprocal with different contexts influencing one another (Weiss et al., 2005), the "C-for-Chinese@JC” project emphasizes the combination and interaction of efforts from home, school and community for local NCS kindergarteners' achievement in Chinese language learning.

\subsection{School Domain}

The school level involves all the aspects in the school system, such as educational materials, school policy, school physical environment and social climate, and teacher quality. In the study done by Kamps et al. (2003), students studying on a reading mastery curriculum had better results in reading fluency than those learning with a literature-based curriculum. That said, educational materials always play an important role for students' success. Viewing this, designing suitable learning materials for EM students is important. Currently, in Hong Kong, the NCS students are taught together with the CS children. However, most NCS students have lower Chinese language proficiencies than their CS counterparts. Having students with different learning abilities in the same classroom requires a differentiation of instruction apart from good materials. In teaching, "differentiation is defined as working to address the abilities, interests, and needs (both perceived and real) of individuals. Differentiation provides students with opportunities to approach curriculum from their strengths, as varied as these might be" (Sondergeld \& Schultz, 2008: p. 35). When teachers adjust the teaching content, process, questioning and evaluation methods, as well as the learning environment in accordance with students' ability and interest, children can maximize their learning effectiveness (Tomlinson, 2000).

Moreover, teacher quality is of prime importance to students' learning. Teacher-student relationships affect students' connectedness to schools (Patrick et al., 2000) as well as their learning interest. However, teachers expressed inadequate knowledge on how to work with diverse groups of students and there 
are problems arising from the lack of communication between parents and families (Suárez-Orozco et al., 2008). As such, providing teachers with professional training or having an adult in the classroom such as a teaching assistant who can understand the cultural and language diversity of the ethnic minority (EM) students would help with a smooth running of the class.

This project attempts to narrow the NCS students' proficiency gap in Chinese language learning by enhancing teachers' professional awareness, knowledge and skills, and culturally responsive (CR) pedagogies aligning with the development of differentiated learning materials for kindergartens developed by the project. In addition to the differentiated learning materials, teachers also apply differentiated pedagogies. During class, teachers would adjust the teaching process, way of questioning, and assessments between CS and NCS students to address their different learning needs and abilities.

\subsection{Home Domain}

Parental involvement has been found to be positively associated with children's school performance (Sheldon \& Epstein, 2005; Jeynes, 2005). Regarding students' literacy performance, studies have revealed that interventions involving parents enhanced children's interest and duration for reading than those without parent involvement (Morrow \& Young, 1997); moreover, research shows that when young children were provided with stimulating reading and writing activities at home, they had better early literacy and oral language skills which are vital to their future academic pursuit (Purcell-Gates, 1988; Whitehurst \& Lonigan, 1998). According to Sheldon (2003), effective home-school collaboration was significantly associated with higher percentages of students who scored satisfactory or above in reading. Therefore, engaging parents into school affairs has a great impact on children.

Epstein (1994) identified that the spheres of family, school, and community do not exist as individual spheres but overlapping with one another to influence a child's education, and developed a "family-school partnership framework" (Epstein, 2001) including six types of parent involvement: parenting (i.e. help families with parenting skills for supporting the child's academic growth); communicating (i.e. ensure a two-way communication exists between home and school about school programs and the child's academic progress); volunteering (i.e. recruit, train, and schedule family volunteers, and support for their work with both school and child); learning at home (i.e. promote family involvement with the child's studies such as homework, and develop interactive home activities for the child and family members); decision-making (i.e. offer opportunities for family to participate in school decision making); collaborating with the community (i.e. coordinate community resources and services for the child, family and school through social services providers and higher education institutions). The framework of parent involvement has mobilized the support from home, school, and community to contribute to the success of the child's educa- 
tion.

At family level, NCS parents have limited proficiency on Chinese language. This causes difficulties in their communication with schools and also in their monitoring of children's learning progress. Therefore, assistance to parents' learning of Chinese language is essential to equip well the NCS families, both parents and children, to be more adapted to the education system in Hong Kong.

\subsection{Community Domain}

By adding "community" to the home-school partnership, it recognizes the resources available within the community that could benefit children and families in the educational process. As stated by Suarez-Orozco et al. (2010), "the goals of students cannot be divorced from the goals of the community, and schools and community agencies will both be more successful if their efforts are joined" (p. 23). Families have access to the community resources, such as child care, medical care, and academic assistance, freeing families to more involvement in educational-related activities which promote their children's academic progress. For the contribution to students' educational success, it is vital to connect school with community.

Since language barriers and cultural values may prevent parents from involving in their children's education, Grant and Ray (2019) have stated that to effectively support parent involvement, it is important for schools to have partnership with community agencies that are familiar with or are already working with specific populations. By providing programs which help minority language parents support their children's learning of the majority language, these parents come to understand their vital role and are given an opportunity to encourage their children's learning. With appropriate parent programs, families may reinforce a positive attitude toward learning the majority language at home (Clayton, 2003).

NCS families in Hong Kong are usually partitioned from the Chinese community so the NCS parents and children are exposed to an environment less favorable to acquire Chinese language. Hence, it is important to bridge NCS students' in-school and after-school learning experiences. A series of intervention programs has been designed and implemented in the three domains of school, home and community holistically as detailed below.

\subsection{School Domain Interventions}

Storybook differentiated learning and teaching materials. A series of storybooks graded into three levels for kindergarten one to three (K.1 to K.3) is developed. These differentiated materials, aiming to address the diversity of NCS students that hinders their learning of Chinese, allow flexibility for teachers' adoption based on different class and school contexts.

Multicultural Teaching Assistants (MTAs). MTAs are trained to support the 
Chinese learning of NCS kindergarteners and keep track of their progress in school. Also, the role of MTAs includes facilitating the communication between parents and teachers. Most MTAs speak their mother tongues, Chinese, and English and their mother tongues are mostly Urdu, Nepalese, and Hindi.

School-based support. School development officers from the university provide intensive support for kindergarten teachers and MTAs, working collaboratively in designing lesson plans and designing curriculum incorporating CR pedagogies into the school curriculum on a regular basis with class observation and feedback on teaching.

Principal and teacher professional development. A course is designed for both principals and teachers to equip them with knowledge and skills for applying inclusive education to address the needs of NCS kindergarten children.

\subsection{Home Domain Interventions}

Parent-led home activities. NCS parents join group workshops to learn basic Cantonese and prompting skills prior to the parent-led home activities, then they can interact with their children in Cantonese at home. In addition, tailor-made learning goals and methods are discussed between social workers and parents. There are also follow-up meetings to review the progress, as well as group meetings for experience sharing.

Parent Chinese class. Chinese classes are provided for NCS parents to advance their use of the Chinese language. The content of parent Chinese class is based on the differentiated story-book teaching materials, which aligns the parents with similar curriculum content that their children are learning at the same time.

Parent support group. The parent support group aims to nurture NCS parents' role in enhancing their children's Chinese learning at home. Topics relevant to NCS students' mainstream schooling in Hong Kong are introduced, such as the local educational system and curriculum adopted by kindergartens. Parents having difficulties attending the workshops are provided with online materials by NGOs to facilitate self-learning.

Parent workshop. The parent workshop creates a platform for NCS parents to meet with Chinese parents for on-going mutual support as a parent community as well as useful information exchange among parents.

\subsection{Community Domain Interventions}

Community exploratory activities. These community activities are conducted in the surrounding spots near NCS students' living places, i.e. a nearby post office or some Hong Kong landmarks such as the Science Museum. CS volunteers recruited interact with NCS students in Cantonese and that makes the children practise Chinese more in activities. The activities also help NCS students build up a network in their own living community while knowing the city broadly.

Cross-cultural activities. These activities are organized to facilitate cultural exchange between NCS and CS kindergarteners and their parents through 
building the connection with Chinese parents and their students.

One to One mentorship scheme. Chinese-speaking volunteers are trained to give regular one-on-one support to NCS children at their home or in a safe nearby area. The scheme aims to cultivate the interest and boost the confidence of NCS students in learning Chinese through games and activities.

Chinese language centre. The Chinese Language Discovery Centre is a play-based and outside-classroom learning centre, providing children with support of reading and writing development, media exploration, and simulation of real-life experience with drama, toys, and puzzles.

\section{Present Study}

This paper aims to:

1) validate the using of H-S-C framework in supporting of Chinese language acquisition in NCS kindergarteners

2) assess the program effectiveness in home, school, community domains

In order to have a comprehensive understanding of the effectiveness of the H-S-C framework on students' Chinese learning, this study has employed the mixed methods approach with different evaluation methods, including the objective outcome evaluation, case study, subjective outcome evaluation, and governmental document review, from multiple sources of informants. As stated by Denzin (2012), making use of "multiple methodological practices, empirical materials, perspectives, and observers in a single study is best understood as a strategy that adds rigor, breadth complexity, richness, and depth to any inquiry" (p. 82). Written consents were obtained from all participants who have joined the "C-for-Chinese@JC" project, including students, parents, teachers, and school principals before data collection. In the following, different evaluations used in different intervention domains and the related results will be presented.

\section{Methodology}

\subsection{Overall Assessment of the H-S-C Framework}

\subsubsection{Objective Outcome Evaluation - Chinese Language Proficiency Participants}

Eighty-eight NCS students (50 males, 38 females) from 6 local kindergartens were involved for this section. Upon the beginning of the study at K1, their mean age was 40 months $(\mathrm{SD}=4.02)$. The ethnicity of the students consisted of Nepalese (42\%), Pakistani (30.7\%), Indian (18.2\%), Filipino (3.4\%), Vietnamese (2.3\%), White (2.3\%), and mixed (1.1\%).

An additional 240 NCS students (117 males, 105 females, 18 unknown) were recruited from local kindergartens to act as a comparison group. They consisted of 80 students each at the K1, K2, and K3 levels. The ethnicity of the students included Pakistani (36.8\%), Nepalese (34.6\%), Indian (17.5\%), Filipino (2.6\%), Vietnamese (0.9\%), White (0.9\%), mixed (1.7\%) and other EM (5\%).

\section{Instruments}


Participants' Chinese language ability was assessed by the Chinese Language Learning Progression Framework for Non-Chinese Speaking Children in Kindergartens in Hong Kong (LPF) (Lam, Hui, \& Cheung, 2018) in the four time points. Detailed information of the instrument can be found at the websites of Centre for Advancement of Chinese Language Education and Research and the Education Bureau. The development of the framework was financially supported by the Quality Education Fund, the Education Bureau. It is developed to measure NCS preschoolers' basic competence in Chinese and there are a number of professional training workshops conducted to brief educators on the use of this framework (Quality Education Fund, 2017). Unlike other assessments which are designed to measure specific language skills of children (for example, grammatical skills or Chinese character recognition), the LPF aims to test children's competence in the use of language Chinese to achieve communicative purpose. Taken into account the theories of first and second language development of young children, effective pedagogy of second language teaching, and second language assessment around the world, and development of LPF has undergone rigorous procedures including expert group discussion, focus group discussion, and a pilot program before the confirmation of the present version of LPF (Lam et al., 2018).

Each assessment contains of two papers. Paper I assesses students' listening and speaking abilities. For listening domain, NCS students' understanding of verbal commands, questions, descriptive content, and informational content are evaluated; and for the speaking domain, students' verbal abilities in answering questions, describing personal experience, providing information, making enquiries or requests, and expressing views or feelings are tested. Paper II assesses students' reading ability-how well they can recognize Chinese characters or components, read aloud text, retell text, link text with daily life experience, and understand of common daily used words. After the tests, students will obtain marks for different tests according to their performance. An overall score indicating the students' Chinese language proficiency is computed by adding up the scores of the three domains.

\section{Data Collection}

Data was collected at four time points, at the beginning of the 2016-17 school year (K1 pre-test), the end of the 2016-17 school year (K1 post-test), the end of the 2017-18 school year (K2 post-test), and the end of the 2018-19 school year (K3 post-test). As the beginning of $\mathrm{K} 2$ was just two months' difference from the end of K1, only the K1 post-test was conducted. Similarly, between the end of K2 and the beginning of $\mathrm{K} 3$, only the $\mathrm{K} 2$ post-test was conducted.

\section{Analysis}

A repeated-measures ANOVA is used to compare the overall Chinese language proficiency score of students at the four time points. It is expected that each time point will see a significantly higher score compared to the previous time point. 
Due to practical limitations a longitudinal control group was not feasible, so a comparison group was used instead, formed from NCS students from K1, K2 and $\mathrm{K} 3$ levels (at the same time point of the post-tests, in a cross sectional manner) not participating in the project. Three welch t-tests will be used to compare if the experimental group performed better compared to the comparison group at the time points. As this involves multiple testing, a Bonferroni correction is applied, meaning that the criterion will be set at 0.017 .

A repeated-measures ANOVA was conducted to investigate the effect of time on overall LPF scores of the 2016-17 1st cohort of NCS students ( $n=88$ ). Mauchly's test indicated that the assumption of sphericity had been violated, $\chi^{2}(5)=48.04, p<0.001$. Therefore, a Greenhouse-Geisser correction was applied, showing a statistically significant difference between time points, $\mathrm{F}(2.17$, 188.58) $=90.64, p<0.001, \eta p 2=0.51$.

Post hoc tests using the Bonferroni correction revealed that raw overall LPF scores were significantly different between the $\mathrm{K} 1$ pre-test $(M=5.66, \mathrm{SD}=5.11)$ and $\mathrm{K} 1$ post-test $(\mathrm{M}=8.31, \mathrm{SD}=5.19, p<0.001)$, between the $\mathrm{K} 1$ pre-test and $\mathrm{K} 2$ post-test $(\mathrm{M}=11.36, \mathrm{SD}=6.38, p<0.001)$, between the $\mathrm{K} 1$ pre-test and $\mathrm{K} 3$ post-test $(\mathrm{M}=17.46, \mathrm{SD}=8.86, p<0.001)$, between the $\mathrm{K} 1$ post-test and $\mathrm{K} 2$ post-test $(p<0.001)$, between the K1 post-test and K3 post-test $(p<0.001)$, and between the K2 post-test and K3 post-test $(p<0.001)$.

As seen in Figure 2, three Welch t-tests revealed that the experimental group had a significantly higher overall LPF score at the K1 post-test when compared to the comparison group $(\mathrm{M}=4.03, \mathrm{SD}=3.45), \mathrm{t}(152.401)=6.35, p<0.001$. At the $\mathrm{K} 2$ post-test, the experimental group also had a significantly higher overall LPF score compared to the comparison group $(\mathrm{M}=8.49, \mathrm{SD}=8.50), \mathrm{t}(145.802)$ $=2.46, p=0.015$. At the $\mathrm{K} 3$ post-test, the experimental group maintained a significantly higher overall LPF score compared to the comparison group $(\mathrm{M}=$ $10.77, \mathrm{SD}=9.73), \mathrm{t}(160.254)=4.65, p<0.001$.

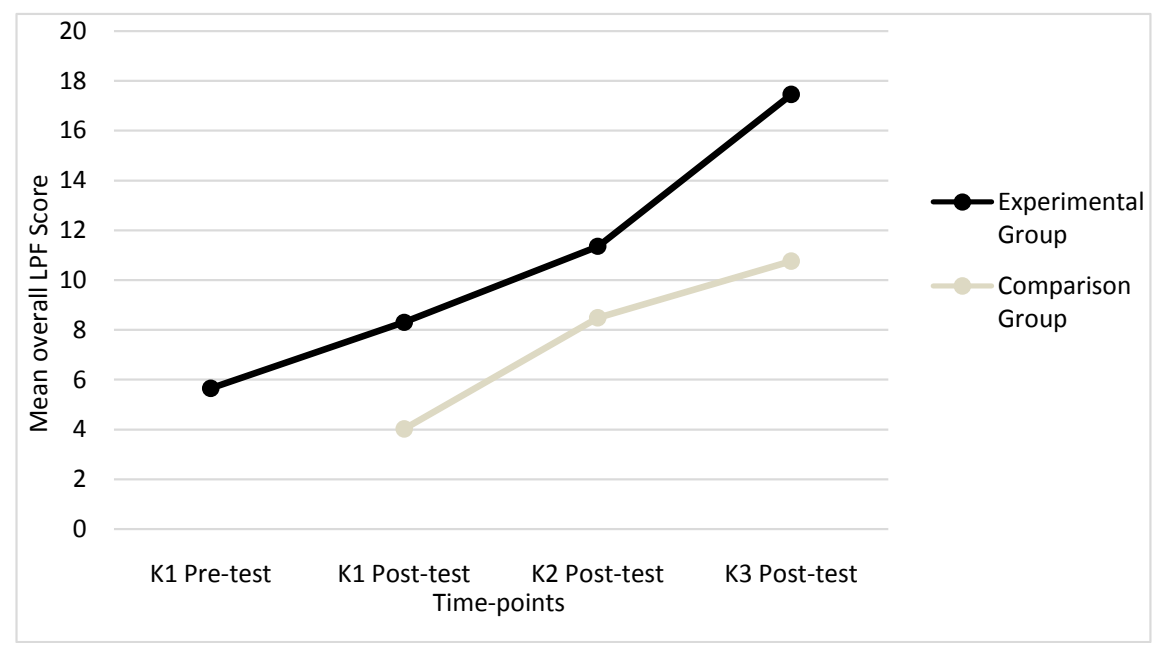

Figure 2. Comparison of overall LPF scores between experimental group and comparison group against four time-points. 
All 88 NCS students of the 2016-17 intake received intervention of the Project programs under the $\mathrm{H}-\mathrm{S}-\mathrm{C}$ framework through the whole stage of kindergarten education from $\mathrm{K} 1$ to $\mathrm{K} 3$. The above improving LPF assessment pre- and post-test scores over three years show that intervention programs of the Project have enhanced the Chinese language proficiency of the students effectively, with the greatest improvement observed during their K3 studies. Students receiving the intervention also performed statistically better at the $\mathrm{K} 1, \mathrm{~K} 2$, and $\mathrm{K} 3$ post-tests compared to those who did not, meaning that the H-S-C framework overall is effective at improving the Chinese language proficiency of NCS kindergarten students.

\subsubsection{Case Study of High Gain Score (HGS) and Low Gain Score (LGS) Students \\ Participants and Procedures}

Twenty NCS students (8 males, 12 females) from 2017-18 intake were involved, 10 students had the greatest improvements (i.e. HGS) and 10 with the least improvements in their overall LPF scores (i.e. LGS) when comparing their K1 pre- and post-tests. The ethnicity of the students consisted of Nepali (65\%), Pakistani (25\%), Filipino (5\%) and Jamaican (5\%).

In order to uncover the possible factors that could explain the performance difference between HGS and LGS students, case studies were conducted at two time points: at the beginning and the end of the 2017-18 school year. In the present study, we only assess how participation rate in the programs under the H-S-C framework contributes to the improvements in NCS kindergarten students' Chinese language proficiency.

\section{Analysis}

Mean participation rates of HGS and LGS students in all programs under the $\mathrm{H}-\mathrm{S}-\mathrm{C}$ framework were computed and then compared to uncover if there were any visible differences between the two groups (Table 1, Table 2).

Results

Table 1. Participation rate of 10 highest gain scores students.

\begin{tabular}{|c|c|c|c|c|c|c|c|c|c|}
\hline Case No. & $\begin{array}{c}\text { Storybook } \\
\text { instructional Time } \\
\text { (In minutes) }\end{array}$ & $\begin{array}{c}\text { Differentiated } \\
\text { Learning } \\
\text { Material }\end{array}$ & $\begin{array}{c}\text { Parent-Led } \\
\text { Home Programme }\end{array}$ & $\begin{array}{c}\text { Parent } \\
\text { Workshop }\end{array}$ & $\begin{array}{l}\text { Parent } \\
\text { Support } \\
\text { Group }\end{array}$ & $\begin{array}{l}\text { Community } \\
\text { Activity }\end{array}$ & $\begin{array}{c}\text { yCross-Cultural } \\
\text { Activity }\end{array}$ & $\begin{array}{c}1 \text {-to-1 } \\
\text { mentorship }\end{array}$ & $\begin{array}{c}\text { Chinese } \\
\text { Learning } \\
\text { Centre }\end{array}$ \\
\hline HB_1718_0127 & 450 & No & No & 1 & 0 & 5 & 1 & Yes & 3 \\
\hline HC_1718_0101 & 1225 & Yes & No & 0 & 0 & 7 & 1 & Yes & 4 \\
\hline HE_1718_0102 & 1260 & Yes & Yes & 1 & 18 & 9 & 1 & No & 2 \\
\hline HF_1718_0104 & 1050 & Yes & Yes & 0 & 22 & 7 & 4 & No & 6 \\
\hline HG_1718_0110 & 900 & No & No & 0 & 0 & 2 & 0 & No & 1 \\
\hline HH_1718_0101 & 1050 & Yes & Yes & 2 & 3 & 10 & 1 & Yes & 2 \\
\hline HI_1718_0106 & 750 & Yes & No & 0 & 3 & 13 & 1 & No & 4 \\
\hline HJ_1718_0118 & 750 & Yes & Yes & 0 & 0 & 7 & 7 & No & 4 \\
\hline Mean & 971.5 & I & / & 0.6 & 6.8 & 8.5 & 2.6 & I & 3.4 \\
\hline
\end{tabular}


Table 2. Participation rate of 10 lowest gain scores students.

\begin{tabular}{|c|c|c|c|c|c|c|c|c|c|}
\hline Case No. & $\begin{array}{c}\text { Storybook } \\
\text { instructional Time } \\
\text { (In minutes) }\end{array}$ & $\begin{array}{l}\text { Differentiated } \\
\text { Learning } \\
\text { Material }\end{array}$ & $\begin{array}{l}\text { Parent-Led } \\
\text { Home } \\
\text { Programme }\end{array}$ & $\begin{array}{c}\text { Parent } \\
\text { Workshop }\end{array}$ & $\begin{array}{l}\text { Parent } \\
\text { Support } \\
\text { Group }\end{array}$ & $\begin{array}{c}\text { Community } \\
\text { Activity }\end{array}$ & $\begin{array}{c}\text { Cross-Cultural } \\
\text { Activity }\end{array}$ & $\begin{array}{c}1 \text {-to-1 } \\
\text { mentorship }\end{array}$ & $\begin{array}{c}\text { Chinese } \\
\text { Learning } \\
\text { Centre }\end{array}$ \\
\hline AL_1718_0129 & 450 & No & No & 2 & 0 & 2 & 0 & No & 2 \\
\hline BL_1718_0108 & 600 & No & No & 0 & 4 & 4 & 0 & No & 3 \\
\hline CL_1718_0114 & 600 & No & No & 0 & 0 & 3 & 0 & No & 3 \\
\hline DL_1718_0126 & 600 & No & No & 0 & 0 & 3 & 0 & Yes & 3 \\
\hline EL_1718_0135 & 600 & No & No & 0 & 0 & 2 & 0 & No & 4 \\
\hline FL_1718_0166 & 600 & No & No & 0 & 2 & 2 & 0 & No & 3 \\
\hline GL_1718_0171 & 600 & No & No & 0 & 0 & 2 & 0 & No & 3 \\
\hline HL_1718_0178 & 600 & No & No & 0 & 0 & 0 & 0 & No & 1 \\
\hline IL_1718_0182 & 600 & No & No & 0 & 0 & 2 & 0 & No & 4 \\
\hline JL_1718_0120 & 900 & Yes & No & 0 & 0 & 2 & 0 & Yes & 3 \\
\hline Mean & 615.0 & I & 1 & 0.2 & 0.6 & 2.2 & 0.0 & 1 & 2.9 \\
\hline
\end{tabular}

\section{Home Domain.}

Five out of ten students and their parents of the HGS group participated in the Parent-led Home programme and had a mean Parent Support Group attendance of 6.8 times over a school year, with 6 parents participating at least 3 times. In contrast, none of the ten students and parents in the LGS group participated in the Parent-led Home programme and had a mean Parent Support Group attendance of 0.6 times over the same period, with 8 parents not participating in the group at all. It indicates that parents of the HGS group participated more in both programs supporting them in relation to effective Chinese learning. Although the mean attendance of the Parent workshop did not differ as drastically, it is worth noting that half of the parents in the HGS group participated at least once, compared to only one parent in the LGS group participating twice, with the others not participating at all.

The results from the home domain programmes suggested that participation in the Parent-led Home programme and the Parent support group may be linked to greater improvements in Chinese language proficiency for NCS students.

\section{School Domain.}

Students in the HGS group had an average storybook instructional time of 971.5 minutes over a school year, compared to only 615 of the LGS group. Also, eight out of ten students in the HGS group were taught using differentiated storybooks learning materials, compared to only one out of ten in the LGS group.

The results suggested that both storybook instructional time and the use of differentiated storybooks materials contribute to greater improvements in Chinese language proficiency for NCS students.

Community Domain.

The mean number of community activity sessions participated by students in 
the HGS groups were higher at 8.5 compared to only 2.2 in the LGS group over a school year. Students in the HGS group also participated in cross-cultural activities with an average of 2.6 sessions, whereas the LGS group did not participate in cross-cultural activities at all. Participation rates in the 1-to-1 mentorship and the Chinese Learning Centre activities did not seem to differ much between the two groups.

The results suggested that participation in community and cross-cultural activities may contribute to greater improvements in Chinese language proficiency for NCS students.

\subsubsection{Government Quality Assurance Document Review Relating to Schools with NCS Students \\ Quality Assurance in Local Government Subsidized Kindergartens}

With the establishment of Quality Assurance Framework, the EDB of the Hong Kong Government is to ensure the continuous improvement in teaching and learning in local government subsidized kindergartens. Quality review (QR) is conducted by external experts in early childhood education in accordance with the Performance Indicators. QR includes document revisions, class observations, and stakeholder interviews. Upon the completion of the QR, a QR report will be issued (Education Bureau, 2018a, 2018b) as an official document which captures the areas of good performance of a kindergarten.

\section{Data Collection and Analysis}

Quality Assurance reports on the network schools were obtained online through the EDB website around the end of 2019. These network schools promised only to implement the interventions of "C-for-Chinese@JC" for Chinese language development of their NCS students. Sections of the reports related to NCS students are first extracted, then common impacts on schools are identified.

Results

To support NCS children, seeking external support for NCS children is in the right direction (Kindergarten Inspection Section, 2017c). With this respect, the "C-for-Chinese@JC" project has adopted the H-S-C framework which caters for the diverse needs of NCS children in different aspects. Moreover, the project also has provided school development officers to help individual kindergartens formulate school-based Chinese learning plans. The followings have shown how the project has facilitated kindergartens in delivering Chinese learning support for NCS children in local government subsidized kindergartens.

\section{Home Domain.}

Focusing on parent education is another area to help NCS students integrate into the society (Kindergarten Inspection Section, 2016c; 2017b; 2017f). The connection between NCS families and kindergartens has been strengthened through parent seminars and workshops. In addition, as there are difficulties in communication between teachers and NCS parents, kindergartens have made use of NCS teachers (for example, multicultural teaching assistants) (Kindergarten Inspection Section, 2017a; 2017d; 2019) to solve the problem. 


\section{School Domain.}

Most kindergartens have reported to make good use of outside resources to enhance the Chinese learning of NCS students by joining professional support programs. First, these kindergartens have arranged teachers to attend teachers' workshops and professional seminars to upgrade their pedagogical knowledge and teaching skills to cater for the needs of NCS students (Kindergarten Inspection Section, 2016a; 2016b; 2017c; 2017f; 2018b; 2019), which is featured by the "C-for-Chinese@JC" project. Second, the schools have adjusted their school-based curriculum in order to raise the interests and learning motivation of NCS students to learn Chinese (Kindergarten Inspection Section, 2017e; 2019), attributing to school development works of the project. For instance, one school has deployed one Chinese teacher to each class as well as allocating more time in activities conducted in Cantonese so as to increase the Chinese learning experiences of NCS students (Kindergarten Inspection Section, 2018a). Another school has adjusted the learning progress and homework loads for NCS students to suit their learning performance (Kindergarten Inspection Section, 2017d).

Community Domain.

Kindergartens also have arranged or encouraged NCS students and their families to participate in community activities, such as visits or workshops, to understand more about community lives and the local education system (Kindergarten Inspection Section, 2016c; 2018b; 2019).

\subsection{Assessment in the Home Domain Interventions}

\section{Subjective Outcome Evaluation from Parents in Home Domain} Interventions

\section{Participants and Data Collection}

Parents who participated in the home-domain programs were invited to complete questionnaires for the programs respectively. The 2016-17 school year was the first year of project implementation and programs were only implemented in six kindergartens. For the Parent Chinese Class, the number of parent participants was 16 and 15 completed questionnaires were collected which showed a high response rate. For the Parent Support Group, 57 completed questionnaires were collected in the 2017-18 school year.

\section{Instruments}

Parent Chinese Class.

A semi-structured questionnaire asking respondents about course effectiveness, confidence in using Chinese after participating the course, and daily Chinese language usage after participating the course. The questionnaire also includes open-ended questions for parents to elaborate on their thoughts on the Parent Chinese Class.

\section{Parent Support Group.}

The questionnaires used include closed-ended questions on parent awareness and knowledge and skills in helping children learn Chinese, as well as open-ended 
questions asking parents on their thoughts on the program.

\section{Analysis}

Questionnaires were analyzed to see if NCS parents considered the different programs to be effective in building their capacity in supporting their children's learning Chinese. Comments from open-ended questions were grouped according to recurring themes.

Results

Parent Chinese Class.

Results in Table 3 suggested that the Parent Chinese Class achieved its aim of equipping NCS parents with basic Chinese language skills. All parents agreed that the classes were organized in a way that helped them do so, and they felt that their Chinese proficiency is better, with increased confidence in speaking and listening to Chinese. The classes also inspired them to pursue further learning in Chinese. Practically speaking, all parents were able to use Chinese at least once a day, both on their own and with their children, with more than $40 \%$ using Chinese with their children more than once a day.

Open-ended comments revealed that parents found the course useful. They stated that the best of the course was "getting to know more people". Undoubtedly, helping parents build their own networks of friends is fundamentally essential for facilitating smooth social integration by engaging them in different aspects of daily living.

Parents had positive comments on the course materials and the course teachers. They regarded the teachers as very good and friendly. They also appreciated on the "teaching method", which includes the teachers' practice on "reviewing (what they had learnt)" before starting each lesson, and their patience in "repeating all things once again" in the course.

Table 3. Parents' views toward to Parent Chinese Class.

\begin{tabular}{lcccc}
\hline & General perception of the program: & & Strongly Agree (\%) \\
\hline & Strongly Disagree (\%) & Disagree (\%) & Agree & \\
\hline $\begin{array}{c}\text { The course was organized in a way that helped } \\
\text { me achieve its learning outcome. }\end{array}$ & 0 & 0 & 46.6 & 53.3 \\
The course inspired me to pursue further \\
$\begin{array}{c}\text { learning in Chinese. } \\
\text { I feel my Chinese proficiency is better. }\end{array}$
\end{tabular}


Parents clearly stated that the course had been useful to them in their daily lives not only in helping them teach children but also being good for their future as well as the course would "do a lot in (her) future", as supported by one parent, it is "real survival Cantonese that I can use right away in daily life". The best thing about the course stated by another parent was "(having) fun games that never let me (her) sleep during the classes". Parents wished that the course could be continued with less non-Chinese speaking time "(for) English, Korean or Urdu ..." during the course, as elaborated by one parent, "we don't have to understand every word and a lot of Cantonese input will help us in the future."

\section{Parent Support Group.}

All parents thought that the Parent Support Group was able to facilitate them in helping their children learn Chinese. Of the parents who responded, all thought that they gained more knowledge and skills in supporting their children in learning Chinese, and that the group raised their awareness towards supporting their children in learning Chinese. No comments were given in the open-ended questions (Table 4).

\subsection{Assessment in the School Domain Interventions}

\subsubsection{Subjective Outcome Evaluation of the Professional Training Programs \\ Participants and Procedures}

In the 2017-18 school year, six principals and 25 teachers participating in the school leadership workshop, and 16 principals and 54 teachers participating in the teacher professional training program were invited to complete a questionnaire after the training programs.

\section{Instruments}

A semi-structured questionnaire includes a question on whether principals and teachers found the school leadership workshop and the teacher professional training program useful in their school practices, supporting NCS students in learning Chinese. It also includes an open-ended question for additional elaboration.

\section{Results}

There were $90.32 \%$ principals and teachers considering the school leadership workshop to be useful in their daily school practices. Teachers mentioned that the workshop deepened their Chinese knowledge, and also increased their understanding towards NCS parents and families in Hong Kong.

The majority of principals and teachers (90\%) considered the teacher professional training program useful for them in supporting NCS students in learning Chinese at school. In particular, most comments mentioned their appreciation towards the inclusion of a cultural element in the program. Teachers had a better understanding about NCS cultures and religions, and better understood NCS students' Chinese proficiency levels along with how to adjust their teaching methods and expectations accordingly after participating in the program and were reminded of the importance of being culturally responsive. 
Table 4. Parents' views toward parent support group.

\begin{tabular}{lcccc}
\hline & \multicolumn{2}{c}{ Strongly Disagree (\%)Disagree (\%) } & Agree (\%) & Strongly Agree (\%) \\
\hline The group was organized in a way that helps me achieve its outcome & 0 & 0 & 21.1 & 78.9 \\
I gained more knowledge and skills in supporting my kids to learn Chinese 0 & 0 & 17.5 & 15.8 \\
My awareness of supporting my kids to learn Chinese is raised & 0 & 0 & 12.3 & 12.3 \\
\hline
\end{tabular}

\subsubsection{Subjective Outcome Evaluation of Multicultural Teaching Assistants (MTA) \\ Participants and Procedures}

In the 2017-18 school year, 24 MTAs were invited to fill in a Student Evaluation of Teaching and Learning (SETL) questionnaire; and 18 principals and 74 teachers were invited to fill in a semi-structured questionnaire.

\section{Instruments}

\section{SETL Questionnaire.}

The SETL questionnaire measures the effectiveness of the course in facilitating learning of students, and the teaching effectiveness of the course implementers on a 4-item scale (strongly agree, agree, disagree, and strongly disagree). Open-ended questions are included at the end for further elaboration. The questionnaire was developed by The University of Hong Kong and has proven reliability and validity (The University of Hong Kong, 2012).

Principal \& Teacher Semi-structured Questionnaire.

Principals and teachers were asked to rate their satisfaction toward MTAs' performance on a four scale (very unsatisfied, unsatisfied, satisfied, and very satisfied).

\section{Analysis}

Percentage distributions were generated for each statement of the MTA SETL questionnaire to compare the proportion of MTAs that consider the training course effective versus those who do not. The results from the principal and teacher questionnaire were then used to verify whether they also consider the MTA training course to be effective. Open-ended questions from both questionnaires were categorized according to recurring themes.

Results

As shown in Table 5, all MTAs understood the expectations and content of the course, and found the course organisation helpful and effective in allowing them to achieve the learning outcomes. They also agreed that the course inspired them to pursue further learning in the subject and in related skills. Moreover, all MTAs provided positive feedback to the teachers. They agreed that the teachers helped them understand key concepts, ideas and issues addressed in the course, and were intellectually stimulated. They also agreed that the teachers were supportive and provided opportunities for students to interact and collaborate.

The open-ended comments given by MTAs showed that they appreciated the practicum of the course and they also found the course fruitful in terms of course design. Many MTAs appreciated the fun teaching approach of teachers, and thought that the teachers were patient, helpful and encouraging. They also enjoyed learning teaching techniques from the course. 
Table 5. MTA SETL questionnaire.

Strongly disagree (\%) Disagree (\%)Agree (\%) Strongly agree (\%)

\section{Learning}

I was clear about what I was expected to learn and achieve in this course.

The course was organized in a way that helped me achieve its learning outcome.

The course inspired me to pursue further learning in the subject/skills.

Overall, the course was effective in helping me achieve the course learning outcomes.

\section{Teaching}

The teachers were able to help me understand the key concepts, ideas and issues addressed in this course.

I was intellectually stimulated and inspired by the teachers.

The teachers provided opportunities for me as well as other students to interact/collaborate in the course.

Overall, the teachers were supportive when I needed help in this course.
0

\section{0}

政

0

0

(n)

0

66.7

0

0

70.8

29.2

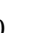

79.2

20.8

25.0

0

0

62.5

37.5

0

0

54.2

45.8

0

0

58.3

41.7

0

50.0

50.0

Regarding the feedback from principals' and teachers' questionnaire, $81.5 \%$ of principals and teachers were satisfied with the overall performance of MTAs, with only $5.4 \%$ unsatisfied, expecting MTAs to be more proactive and involved in lesson preparation and teaching activities.

\subsubsection{Subjective Outcome Evaluation toward the Differentiated Learning Materials \\ Participants and Procedures}

Questionnaires were distributed to all project participating schools to collect their views toward the differentiated learning materials for the 2017-18 school year, finally 18 principals and 74 teachers responded to the questionnaire.

\section{Instruments}

A semi-structured questionnaire asking respondents satisfaction level in four areas of the learning materials: compatibility with existing curricula, compatibility with abilities of students, attractiveness of materials to students, and cultural responsiveness of materials. Open-ended questions are included at the end for additional elaboration.

\section{Analysis}

Percentages of each statement on the questionnaire is calculated and compared to determine if principals and teachers found the differentiated learning materials performing well in the four areas.

\section{Results}

Table 6 shows that most principals and teachers were satisfied with the differentiated learning materials, in terms of compatibility with the existing curricula (80.4\%), compatibility with students' abilities (85.3\%), appealing to students (88.6\%), and culturally responsiveness (90.2\%). 
Table 6. Principals' \& teachers' views toward the differentiated learning materials.

Very unsatisfied (\%) Unsatisfied (\%) Satisfied (\%) Very satisfied (\%)

1) Compatibility with existing curricula

Story-based teaching materials match with theme-based learning and teaching activities

$\begin{array}{llll}1.1 & 6.5 & 60.9 & 21.7 \\ 2.2 & 10.9 & 67.4 & 9.8 \\ 0 & 8.7 & 65.2 & 16.3 \\ 1.1 & 8.7 & 64.5 & 15.9\end{array}$

Story-based teaching materials connect with school-based curriculum

Content of story-based teaching materials corresponds with

"Kindergarten Curriculum Guide 2017"

Average

2) Compatibility with ability of students

Content of story-based teaching materials matches with multicultural (NCS)students' ability

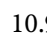

56.5

Content of story-based teaching materials matches with local (CS) students' ability

Average

3) Attractiveness of materials to students

Story-based teaching materials are interesting and help students learn Chinese

Story-based teaching materials are interesting and motivate students to learn

\section{4) Cultural responsiveness of materials}

One principal commented that the materials suited their kindergarten's themes, and that teachers were able to apply cultural responsiveness in their teaching, which was reflected in pleasurable and integrated learning of NCS and CS students. One teacher commented that the materials were relatable to daily life.

\subsection{Assessment in the Community Domain Intervention}

\section{Subjective Outcome Evaluation of the Community Programs}

\section{Participants and Procedures}

Different community activities were organized and implemented by two non-governmental organizations with both NCS and CS participants. After the programs, principals and teachers were invited to complete a questionnaire. In the present study, 18 principals and 74 teachers were involved.

\section{Instrument}

A semi-structured questionnaire consists of two questions asking respondents' satisfaction on community exploratory and cross-cultural activities. Open-ended questions are also included at the end for additional elaboration.

Analysis 
Percentages of principal and teachers satisfied and unsatisfied with the community exploratory and cross-cultural activities are calculated, and comments from open-ended questions are categorized according to recurring themes.

Results

Over half of the principals and teachers (65.2\%) were satisfied with the effectiveness of both community exploratory activities and cross-cultural activities, with only $7.6 \%$ unsatisfied for community activities and 5.4\% unsatisfied for cross-cultural activities. One principal and a few teachers commented that the activities allowed NCS students to gain new life experiences and knowledge, based on their previous knowledge. One principal and another teacher also mentioned that the activities were pleasurable for the students.

\section{Discussion}

Overall, results indicate that using interventions under the H-S-C framework was successful in improving the Chinese language proficiency of NCS students, as evidenced by the longitudinal study which showed increasing Language Proficiency Framework scores from $\mathrm{K} 1$ to $\mathrm{K} 3$. At any given time-point during this period, NCS students receiving H-S-C framework-related interventions also performed better than those who did not, meaning that the framework-related interventions were more effective compared to current approaches for learning and teaching of Chinese for NCS students. The successful of the H-S-C framework was further confirmed by the case study on "top ten" students' performance as well as the Quality Assurance reports from the Hong Kong government.

The effects of all the inputs within the three domains culminate in the overall improvement in Chinese language proficiency and better social integration observed in the experimental group of NCS students in this study. The capacity building of NCS parents, principals, teachers, and MTAs in supporting NCS students' learning Chinese, and the development of appropriate differentiated learning materials and community programs, together serve the common purpose of recreating L1-like language learning environments for NCS students. This hinges on home, school, and community domains playing their respective roles.

Within the home domain, the study was the first of its kind in systematically building the capacity of NCS parents in supporting their children to learn Chinese as a second language, in the areas of parent awareness, parent Chinese language proficiency, knowledge of community resources, schooling information, and parenting skills. All home domain activities were well-received by parents and after these activities, parents were more confident in using Chinese, and they all agreed that they were better equipped to support their children in learning Chinese.

Evidence in the school domain interventions also points to the success in capacity building of principals and teachers. Firstly, the professional training programs were thought to equip educators with practical skills of effective teaching 
methods and enhance the awareness of the cultural diversity of NCS students. Secondly, MTA, a post created to assist NCS students in learning Chinese in the school environment, was perceived by principals and teachers as helpful in delivering CR teaching and learning in classes, as well as being the communication bridge between schools and NCS parents. MTAs also thought themselves being able to perform the intended roles in the classrooms and they were being equipped with professional skills. Thirdly, the development of differentiated teaching materials, was able to cater to diverse language abilities and cultural backgrounds of NCS and CS students. The teaching materials were attractive to facilitate students' learning, and being culturally appropriate for both NCS and CS students. The materials were also compatible with school-based curricula, and also with the curriculum recommendations from the Hong Kong government.

For the community domain activities, results indicated that they could provide experiential learning for NCS students to understand and integrate into their local communities, with principals and teachers mentioning that the activities allowed NCS students to gain knowledge and life experiences.

The rationale behind adopting an H-S-C framework was to let NCS students experience whole immersion in Chinese environment that would otherwise be only available to local students with Chinese as their mother tongue in homes, schools, and communities (Krashen, 1982; Long, 1996; Brown, 2007). Regarding acquiring Chinese as a second language, it is generally thought that NCS students learn Chinese only as a transitional stage. They are actually expected to gain close to the L1 Chinese language competency under the local system. The CS children's acquisition of Chinese starts to happen naturally at home and in their daily living. Chatting and socializing among peers in the community also contributes to their mother-tongue development. By contrast, except through formal school education, NCS students have limited exposure to environments favourable to learning and practicing Chinese, and it is thus understandable that their learning Chinese is obstructed to a certain extent. The constraint of less exposure of NCS students can be ascribed to less local community participation of some ethnic minorities in Hong Kong society.

To achieve the goal of enhancing effective learning of Chinese of NCS students, the space of learning (Marton \& Tsui, 2004; Tse et al., 2005) has to be created by co-constructing the learning environments in the three domains of home, school, and the community. The space of learning can be regarded as the past experience of a learner that enables him/her to distinguish the differences and similarities in the present learning condition. They should be aware of the critical features of the learning object. This space can be widened if the learners are provided with opportunities to explore the learning object (in the present situation is the learning of Chinese). It is therefore essential to create changes by building the capacities of parents, principals, teachers, and teaching assistants. With improved Chinese language proficiency and better cultural exchange, NCS students are benefited in their future academic studies, such as having better 
opportunities in Primary 1 transition. Also, the CR pedagogy provides NCS students with a better sense of belonging to, and integration into the community. Though collaboration among home, school, and community is promoted in many places, few were well-structured and resourced for its full local implementation for early childhood education. Apart from kindergarteners, this H-S-C approach is also applicable to primary school NCS students for learning Chinese. Learning Chinese as a second or foreign language is a global trend. As reported, there were 6.5 million candidates taking different kinds of Chinese Proficiency Test, a proficiency test for non-native Chinese speakers, in 2017 (Xinhuanet, 2018). Though Cantonese as the spoken Chinese is discussed in the present paper, the H-S-C framework is applicable to Chinese learners all around the world.

\section{Conclusion}

The "C-for-Chinese@JC" project is well-resourced with lots of intervention programs. It is influential to academics, parents, educators, social workers as well as policymakers. As proven in the present paper, the concerted effort from home, school, and community domains is the most effective way to support NCS students; thus it is ideally to have interventions in all three domains. If there is concern about resource, it is suggested to start with the child's microsystem (i.e., parents and teachers) as it has most impacts on one's development. Building the capacity of parents and teachers is probably the first step to enhance the learning effectiveness of NCS students. The study also shows that, for improved learning of Chinese for NCS kindergarten students, the reconstruction of an L1-like environment, through the implementation of an H-S-C framework, should be put into local practice in order to benefit more NCS students.

This paper presents a general validation using multiple sources of evidences, rather than in-depth validation of every single program or activity because of space constraints. Moreover, with limited page length, it is out of the scope of this study to go into all of the many principles behind the implementation of the H-S-C model. It is hoped that these aspects could be addressed in more focused studies in the future.

\section{Funding/Financial Support}

This work and the "C-for-Chinese@JC" project were supported by The Hong Kong Jockey Club Charities Trust.

\section{Conflicts of Interest}

The authors declare no conflicts of interest regarding the publication of this paper.

\section{References}

Bronfenbrenner, U. (1993). The Ecology of Cognitive Development: Research Models and Fugitive Findings. In R. H. Wozniak, \& K. W. Fischer (Eds.), Development in Context. 
Activity and Thinking in Specific Environments (pp. 3-44). Mahwah, NJ: Lawrence Erlbaum.

Brown, H. (2007). Teaching by Principles: An Interactive Approach to Language Pedagogy (3rd ed.). London: Pearson Education.

Census and Statistics Department, HKSAR (2017). 2016 Population by-Census-Thematic Report: Ethnic Minorities. Hong Kong: Hong Kong Census and Statistics Department. https://www.statistics.gov.hk/pub/B11201002016XXXXB0100.pdf

Chen, X., Hao, M., Geva, E., Zhu, J., \& Shu, H. (2009). The Role of Compound Awareness in Chinese Children's Vocabulary Acquisition and Character Reading. Reading and Writing, 22, 615-631. https://doi.org/10.1007/s11145-008-9127-9

Choi, J., \& Ziegler, G. (2015). Literacy Education for Low-Educated Second Language Learning Adults in Multilingual Contexts: The Case of Luxembourg. Multilingual Education, 5, 1-21. https://doi.org/10.1186/s13616-015-0024-7

Clayton, J. B. (2003). One Classroom, Many Worlds: Teaching and Learning in the Cross-Cultural Classroom. Portsmouth, NH: Heinemann.

Curriculum Development Council (1996). Guide to the Pre-Primary Curriculum. Hong Kong: Hong Kong Government Printer.

Curriculum Development Council (2006). Guide to the Pre-Primary Curriculum. Hong Kong: Hong Kong Government Printer.

Denzin, N. K. (2012). Triangulation 2.0. Journal of Mixed Methods Research, 6, 80-88. https://doi.org/10.1177/1558689812437186

Education Bureau, HKSAR (2018a). Education Bureau Circular No. 11/2018, Enhanced Quality Assurance Framework for Kindergarten Education.

https://www.edb.gov.hk/attachment/en/edu-system/preprimary-kindergarten/quality-a ssurance-framework/EDBC18011E.pdf

Education Bureau, HKSAR (2018b). Handbook on Quality Review for Kindergartens. EDB.

https://www.edb.gov.hk/attachment/en/edu-system/preprimary-kindergarten/quality-a ssurance-framework/qr/handbook_on_qr_eng.pdf

Epstein, J. L. (1994, E-Book in 2019). Theory to Practice: School and Family Partnerships Lead to School Improvement and Student Success. In B. Werber, \& C. Fagnano (Eds.), School, Family, and Community Interaction: A View from the Firing Lines (pp. 39-52). New York: Routledge. https://doi.org/10.4324/9780429305375-4

Epstein, J. L. (2001). School, Family, and Community Partnerships: Preparing Educators and Improving Schools. Boulder, CO: Westview Press.

Equal Opportunities Commission, EOC (2019). Closing the Gap: Report of the Working Group on Education for Ethnic Minorities. Hong Kong: Hong Kong Equal Opportunities Commission.

https://www.eoc.org.hk/s/ClosingtheGap/Closing_the_Gap_Report.pdf

Government of HKSAR (2016). LCQ16: Provision of Grants for Kindergartens Admitting Non-Chinese Speaking Students [Press Release]. https://www.info.gov.hk/gia/general/201607/13/P2016071301598.htm

Grant, K. B., \& Ray, J. (2019). Home, School, and Community Collaboration: Culturally Responsive Family Engagement (4th ed.). Thousand Oaks, CA: SAGE Publications, Inc.

Henderson, A. T., \& Mapp, K. L. (2002). A New Wave of Evidence: The Impact of School, Family and Community Connections on Student Achievement. Southwest Educational Development Laboratory.

Jeynes, W. H. (2005). A Meta-Analysis of the Relation of Parental Involvement to Urban 
Elementary School Student Academic Achievement. Urban Education, 40, 237-269. https://doi.org/10.1177/0042085905274540

Kamps, D., Wills, H., Greenwood, C., Thorne, S., Lazo, J., Crockett, J., Swaggart, B. et al. (2003). Curriculum Influences on Growth in Early Reading Fluency for Students with Academic and Behavioral Risks: A Descriptive Study. Journal of Emotional and Behavioral Disorders, 11, 211-224. https://doi.org/10.1177/10634266030110040301

Kindergarten Inspection Section, HKSAR (2016a). Quality Review Report (School No.: 542768). Hong Kong: Education Bureau. (In Chinese)

https://www.edb.gov.hk/attachment/tc/edu-system/preprimary-kindergarten/quality-a ssurance-framework/qr/qr-report/PLK_MrsTamWahChing.pdf

Kindergarten Inspection Section, HKSAR (2016b). Quality Review Report (School No.: 324264). Hong Kong: Education Bureau. (In Chinese)

https://www.edb.gov.hk/attachment/tc/edu-system/preprimary-kindergarten/quality-a ssurance-framework/qr/qr-report/WesternPacific.pdf

Kindergarten Inspection Section, HKSAR (2016c). Quality Review Report (School No.: 320897). Hong Kong: Education Bureau. (In Chinese)

https://www.edb.gov.hk/attachment/tc/edu-system/preprimary-kindergarten/quality-a ssurance-framework/qr/qr-report/SaintMay.pdf

Kindergarten Inspection Section, HKSAR (2017a). Quality Review Report (School No.: 532550). Hong Kong: Education Bureau. (In Chinese)

https://www.edb.gov.hk/attachment/tc/edu-system/preprimary-kindergarten/quality-a ssurance-framework/qr/qr-report/CheLok.pdf

Kindergarten Inspection Section, HKSAR (2017b). Quality Review Report (School No.: 157678). Hong Kong: Education Bureau. (In Chinese)

https://www.edb.gov.hk/attachment/tc/edu-system/preprimary-kindergarten/quality-a ssurance-framework/qr/qr-report/SA_FuKeung.pdf

Kindergarten Inspection Section, HKSAR (2017c). Quality Review Report (School No.: 156272). Hong Kong: Education Bureau. (In Chinese)

https://www.edb.gov.hk/attachment/tc/edu-system/preprimary-kindergarten/quality-a ssurance-framework/qr/qr-report/FuYiu.pdf

Kindergarten Inspection Section, HKSAR (2017d). Quality Review Report (School No.: 325775). Hong Kong: Education Bureau. (In Chinese)

https://www.edb.gov.hk/attachment/tc/edu-system/preprimary-kindergarten/quality-a ssurance-framework/qr/qr-report/MayNga_Br.pdf

Kindergarten Inspection Section, HKSAR (2017e). Quality Review Report (School No.: 157856). Hong Kong: Education Bureau. (In Chinese)

https://www.edb.gov.hk/attachment/tc/edu-system/preprimary-kindergarten/quality-a ssurance-framework/qr/qr-report/RockOfAge_Lutheran.pdf

Kindergarten Inspection Section, HKSAR (2017f). Quality Review Report (School No.: 319562). Hong Kong: Education Bureau. (In Chinese)

https://www.edb.gov.hk/attachment/tc/edu-system/preprimary-kindergarten/quality-a ssurance-framework/qr/qr-report/StBarnaba'sCh.pdf

Kindergarten Inspection Section, HKSAR (2018a). Quality Review Report (School No.: 558346). Hong Kong: Education Bureau.

https://www.edb.gov.hk/attachment/tc/edu-system/preprimary-kindergarten/quality-a ssurance-framework/qr/qr-report/LittleBuds.pdf

Kindergarten Inspection Section, HKSAR (2018b). Quality Review Report (School No.: 582530). Hong Kong: Education Bureau. (In Chinese)

https://www.edb.gov.hk/attachment/tc/edu-system/preprimary-kindergarten/quality-a 
ssurance-framework/qr/qr-report/SinChing.pdf

Kindergarten Inspection Section, HKSAR (2019). Quality Review Report (School No.: 231576) (Translation Version). Hong Kong: Education Bureau. https://www.edb.gov.hk/attachment/en/edu-system/preprimary-kindergarten/quality-a ssurance-framework/qr/qr-report/SI_KwaiKing.pdf

Krashen, S. (1982, E-Book in 2009). Principles and Practice in Second Language Acquisition. First Internet Edition.

https://www.semanticscholar.org/paper/Principles-and-Practice-in-Second-LanguageKrashen/4b85d72a8edbd47b4ba3e0b563f1563f6e9f746b

Lam, W. I., Hui, S. Y., \& Cheung, W. M. (2018). Chinese Language Learning Progression Framework for Non-Chinese Speaking Children in Kindergartens in Hong Kong. Hong Kong: Centre for Advancement of Chinese Language Education and Research.

Legault, J., Zhao, J., Chi, Y.-A., Chen, W., Klippel, A., \& Li, P. (2019). Immersive Virtual Reality as an Effective Tool for Second Language Vocabulary Learning. Languages, 4, 13. https://doi.org/10.3390/languages 4010013

Long, M. H. (1996). The Role of the Linguistic Environment in Second Language Acquisition. In W. C. Ritchie, \& T. K. Bhatia (Eds.), Handbook of Second Language Acquisition (pp. 413-468). Cambridge, MA: Academic Press. https://doi.org/10.1016/B978-012589042-7/50015-3

Marton, F., \& Tsui, A. (2004). Classroom Discourse and the Spacing of Learning [Electronic Resource]. Mahwah, NJ: L. Erlbaum Associates. https://doi.org/10.4324/9781410609762

Morrow, L. M., \& Young, J. (1997). A Family Literacy Program Connecting School and Home: Effects on Attitude, Motivation, and Literacy Achievement. Journal of Educational Psychology, 89, 736-742. https://doi.org/10.1037/0022-0663.89.4.736

Patrick, B., Hisley, J., \& Kempler, T. (2000). “What's Everybody So Excited about?”: The Effects of Teacher Enthusiasm on Student Intrinsic Motivation and Vitality. The Journal of Experimental Education, 68, 217-236. https://doi.org/10.1080/00220970009600093

Pomerantz, E. M., Moorman, E., \& Litwack, S. D. (2007). The How, Whom, and Why of Parents' Involvement in Children's Academic Lives: More Is Not Always Better. Review of Educational Research, 77, 379-410. https://doi.org/10.3102/003465430305567

Purcell-Gates, V. (1988). Lexical and Syntactic Knowledge of Written Narrative Held by Well-Read-to Kindergartners and Second Graders. Research in the Teaching of English, 22, 128-160.

Quality Education Fund, EDB, HKSAR (2017). Report on Development of Chinese Language Learning Progress Framework for Non-Chinese Speaking (NCS) Children in Kindergartens in Hong Kong. https://qcrc.qef.org.hk/Publish/project_information/201712/20130076FR.pdf

Sheldon, S. B. (2003). Linking School-Family-Community Partnerships in Urban Elementary Schools to Student Achievement on State Tests. The Urban Review, 35, 149-165. https://doi.org/10.1023/A:1023713829693

Sheldon, S. B. (2007). Improving Student Attendance with School, Family, and Community Partnerships. The Journal of Educational Research, 100, 267-275. https://doi.org/10.3200/JOER.100.5.267-275

Sheldon, S. B., \& Epstein, J. L. (2005). Involvement Counts: Family and Community Partnerships and Mathematics Achievement. The Journal of Educational Research, 98, 196-206. https://doi.org/10.3200/JOER.98.4.196-207 
Sondergeld, T., \& Schultz, R. (2008). Science, Standards, and Differentiation: It Really Can Be Fun. Gifted Child Today, 31, 34-40. https://doi.org/10.4219/gct-2008-694

Suarez-Orozco, C., Onaga, M., \& De Lardemelle, C. (2010). Promoting Academic Engagement among Immigrant Adolescents through School-Family-Community Collaboration. Professional School Counseling, 14, 15-26.

https://doi.org/10.5330/prsc.14.1.xl6227108g624057

Suárez-Orozco, C., Suárez-Orozco, M., \& Todorova, I. (2008). Learning a New Land: Immigrant Students in American Society. Cambridge, MA: Harvard University Press.

Task Force on Home School Co-Operation and Parent Education (2019). Positive Parenting, Cross-Sector Collaboration and Innovation Foster Healthy Child Development. Hong Kong.

https://www.e-c.edu.hk/doc/en/publications_and_related_documents/education_repor ts/Report_TF\%20on\%20HSC_en.pdf

Tomlinson, C. A. (2000). Differentiation of Instruction in the Elementary Grades (ERIC Digest). Reston, VA: Office of Educational Research and Improvement. (ERIC Document Reproduction Service No. EDD00036)

The University of Hong Kong (2012). Report on a Pilot Study of the Student Evaluation of Teaching and Learning (SETL) Questionnaire.

https://intraweb.hku.hk/reserved_2/tlearn/SETL2012/SETL_Pilot_Report_Full_Versio n.pdf

Tse, S. K., Shum, S. K., \& Ki, W. W. (2005). Variation Theory and Space for Learning. Hong Kong: Hong Kong University Press.

Tsung, L., \& Gao, F. (2012). What Accounts for the Underachievement of South Asians in Hong Kong? The Voices of Pakistani and Nepalese Parents. Educational Research, 54, 51-63. https://doi.org/10.1080/00131881.2012.658199

Weiss, H. B., Kreider, H., Lopez, M. E., \& Chatman, C. M. (2005). Preparing Educators to Involve Families: From Theory to Practice. Thousand Oaks, CA: SAGE Publications.

Whitehurst, G. J., \& Lonigan, C. J. (1998). Child Development and Emergent Literacy. Child Development, 69, 848-872. https://doi.org/10.1111/j.1467-8624.1998.tb06247.x

Xinhuanet (2018). The Number of Candidates Taking Different Kinds of Chinese Language Tests Increased to 6,500,000 in 2017.

http://www.xinhuanet.com/politics/2018-05/29/c_1122906694.htm 